Tesis. Año 14, 13(16), 2020, 11-24

\title{
EI discurso metafórico en la poesía erótica de Carlos Germán Belli
}

\author{
Alejandro Giancarlo Mautino Guillén \\ amautinog@unmsm.edu.pe
}

\section{Resumen}

En este artículo analizamos la función fundamental que tienen los elementos metafóricos en la construcción del discurso erótico en la poesía de Carlos Germán Belli. Desde nuestra perspectiva, las metáforas y los discursos deglutientes y vigilantes en su poética construyen una singular reflexión sobre la cotidianidad del acto erótico a través del cuerpo. Para tal propósito nos apoyamos en la neorretórica y la lingüística cognitiva para entender la relación entre pensamiento-lenguaje vinculados al discurso poético erótico en algunos poemas del autor de Sextinas y otros poemas (1970).

Palabras claves: Discurso, erotismo, sistema metafórico, discurso deglutiente, discurso vigilante.

\section{Abstract}

In this article we analyze the fundamental function that metaphorical elements have in the construction of erotic discourse in the poetry of Carlos Germán Belli. From our perspective, the metaphors and the swallowing and vigilant discourses in his poetry construct a singular reflection on the daily routine of the erotic act through the body. For this purpose we rely on neorethoric and cognitive linguistics to understand the relationship between thought-language linked to erotic poetic discourse in some poems by the author of Sextinas y otros poemas (1970).

Keywords: Speech, eroticism, metaphorical system, swallowing speech, vigilant speech.. 


\section{El discurso metafórico en la poesía erótica de Carlos Germán Belli}

\section{Introducción}

La obra poética de Carlos Germán Belli es vasta. Jorge Cornejo Polar (1994) la ha dividido en cinco etapas. La primera, de búsqueda, corresponde al trabajo formal, a la asimilación de la vanguardia de la primera mitad del siglo XX y a la apertura de la huella clásica en su poesía. A este periodo obedecen textos como Poemas (1958) y Dentro y fuera (1960). La segunda etapa es la del desarrollo del lenguaje belliano y la absorción creativa del legado de las formas hispánicas del Siglo de Oro bajo la perspectiva del universo tecnológico en la modernidad. A este periodo comprenden ; Oh hada cibernética! (1961), El pie sobre el cuello (1964) y Por el monte abajo (1966). La tercera etapa es la del abandono del modelo hispánico y de la sustitución por los modelos itálicos provenzales como la sextina y la canción petrarquista. Abarcan a este periodo textos como Sextinas y otros poemas (1970), En alabanza al bolo alimenticio (1979) y Canciones y otros poemas (1982). La cuarta etapa es el proceso de formalización de la poética belliana, en donde el amor es un tópico de reflexión sobre la plenitud de los amantes. A este periodo corresponden Más que señora bumana (1986) y El buen mudar (1987). Finalmente, la quinta etapa es una poética abierta de la esperanza en el futuro del mundo. A este periodo pertenecen En el restante tiempo terrenal (1988) y ¡Salve, Spes! (2000).

Sobre la propuesta de esta división, la estudiosa italiana Martha L. Canfield (2012) ha agregado una sexta etapa denominada "la celebración de la vida, como un don maravilloso que si bien está destinado a tener un fin (...) está también destinado a renacer constantemente" (p. 5). A este periodo conciernen $E n$ las hospitalarias estrofas (2002), La miscelánea intima (2003) y El alternado paso de los hados (2006) y un conjunto de poemas publicados en su poesía completa: Los versos juntos (2008).

Estas seis etapas muestran los tópicos por los que transita la pluma de Belli y al mismo tiempo rastrean los elementos técnicos y lingüísticos que ha em- 
pleado a lo largo de los años en su poesía. Sin embargo, el estilo belliano se ha mantenido muy a su fuerza: una misteriosa mezcla de tradición y modernidad irrecusable.

Desde nuestra lectura crítica observaremos cómo se construye el discurso erótico en la poesía de Carlos Germán Belli (2008) a partir del análisis de la estructura del sistema metafórico que opera en el discurso erótico de su poética. El discurso metafórico en la poesía de Belli se estructura en función de las metáforas orientacionales, ontológicas y estructurales. De esta manera nos referiremos la simbolización del cuerpo, la representación de la figura femenina y la visión cognitiva del poeta sobre el eros a partir de las metáforas. Asimismo, observamos que predominan dos tipos de discursos eróticos en la poesía de Be1li: el discurso deglutiente y el discurso vigilante. En estos últimos nos interesa detenernos en el lenguaje del cuerpo, en donde la alusión a los elementos corporales y su representación está en relación del funcionamiento del cuerpo como un signo de su sexualidad, de su digestión, de su circulación y de su respiración en torno a su naturaleza vital y trascendente como "ser", que se materializan en un grupo extenso de poemas que resemantizan lo corpóreo en función de alguna actividad humana.

\section{A) Hipótesis y marco metodológico}

La hipótesis principal que planteamos es que el discurso metafórico es parte fundamental de la poética erótica de Carlos Germán Belli. Este ha posibilitado una representación figurativa a partir de la simbolización del cuerpo. De tal manera que, dentro de la operatividad del discurso erótico, podemos señalar tres unidades: un pensamiento metafórico vinculado al erotismo, la correlatividad entre el acto de comer en relación con el acto coital y una visión del cuerpo sometido a un sistema de vigilancia a través del deseo pleno.

En este artículo se desarrollará un estudio crítico valorativo sobre la poesía de Carlos Germán Belli, específicamente sobre aquella que aborda a la temática erótica. Para tal fin utilizaremos métodos como el análisis, la síntesis, el método inductivo, deductivo y descriptivo. Empero, nuestra perspectiva analítica priorizará lo interdisciplinario, pues el discurso literario conjuga con otros campos como la neorretórica y la lingüística cognitiva.

En lo fundamental nos basamos en las contribuciones de la retórica general textual, especialmente de Stefano Arduini (2000), quien plantea que la figura retórica debe entenderse como un universal antropológico de la expresión y no como un desvío respecto de la norma. Asimismo, nos interesan los aportes de la neorretórica que no atiendan únicamente a algunas unidades del discurso retórico como la elocutio, sino que recuperen una dimensión totalizante de esta. Este discurso retórico intenta, de este modo, siguiendo a Arduini, ser un producto lingüístico de la actividad comunicativa del locutor. 
Asimismo, utilizamos los aportes de la Lingüística cognitiva, precisamente para dar cuenta de los procesos cognitivos involucrados en la construcción del pensamiento metafórico. En este sentido nos valemos de los aportes de George Lakoff y Mark Johnson (2009), quienes subrayan que la representación figurativa no es patrimonio exclusivo de la literatura, sino que esta más bien parte de la realidad, dentro de un ámbito particularmente comunicativo. De esta manera podríamos decir que la metáfora es de naturaleza cognitiva y no meramente un recurso de la imaginación poética.

Partamos, en primer orden, del concepto de "discurso" de Jacques Fontanille (2006), quien enfatiza que este:

permite captar no solamente los productos fijados o convencionales de la actividad semiótica (los signos, por ejemplo) sino también, y, sobre todo, los actos semióticos mismos. Pues el discurso es una enunciación acto, y este acto, en principio, es ante todo un acto de presencia: la instancia de discurso no es un autómata que ejerce una capacidad de lenguaje, sino una presencia humana, un cuerpo sensible que se expresa. (p. 71)

De esta manera podríamos subrayar que el discurso es un conjunto donde la significación no es gratuita ni casual, ni se da solo por la adición o unión de sus elementos enunciantes, sino que este persigue un complejo proceso donde las formas significantes comparten nexos. Es así que el discurso es el "área de los procesos de comunicación superiores al enunciado o frase" (Marchese \& Forradellas, 1994, p. 103).

En la obra de Belli el discurso se torna erótico, pues revela no solo el conocimiento del cuerpo (referencialidad) sino un complejo proceso cognitivo (simbolización) que va más allá del amor y el erotismo como una siempre manifestación del instinto sexual.

Como observaremos, el universo figurativo que se desprende de la poética belliana coloca en un plano medular la figura femenina, tal como advertiremos. Sin embargo, esta figura es sometida a un conjunto de sematizaciones que van desde el proceso de metaforización, alegorización, analogización, comparación, simbolización, etc., donde el cuerpo femenino se convierte en un espacio de disputa y tensión, y en donde diversas dinámicas sígnicas operan sobre él.

Verbigracia, Pierre Bordieu (1998) entiende que:

la mujer ha sido pensada a través de analogías entre el cuerpo femenino y la tierra labrada (por el arado masculino) o entre el vientre femenino y el horno, ya sea aprehendida a través de la analogía, típicamente letrada si no literaria, entre el cuerpo de la mujer y la tablilla sobre la que se escribe. (p. 15) 
Como subrayamos líneas arriba, el cuerpo femenino es representado como un complejo espacio de significaciones que están en tensión. En la poesía de Belli, como propondremos a continuación, se ha procurado representar un pensamiento metafórico ligado a la erotización del cuerpo, la correlatividad entre el acto de comer y el deseo sexual y; también, dilucidar cómo es que el cuerpo es sometido a un sistema de vigilancia y de deseo a través de la voz poética.

\section{B. El discurso erótico metafórico}

George Lakoff y Mark Johnson (2009) parten de la idea de que la metáfora es de naturaleza cognitiva y no un recurso de la imaginación poética:

La metáfora [...] impregna la vida cotidiana, no solamente el lenguaje, sino también el pensamiento y la acción. Nuestro sistema conceptual ordinario, en términos del cual pensamos y actuamos, es fundamentalmente de naturaleza metafórica. (p. 39)

Desde esta perspectiva, la metáfora es parte importante de nuestra forma cotidiana de percibir el mundo. Esta rige y organiza nuestra conducta, la forma de conceptualizar nuestra enunciación y nuestras relaciones con las personas en nuestros ámbitos cotidianos, íntimos y sociales.

De este modo, también la metáfora es importante en la poética erótica de Belli. Esta se desenvuelve y se representa en las relaciones más tanáticas y místicas hasta cuestiones más cotidianas y banales. Es así que la representación de estos signos, de la corporización de lo erótico, advierten del mecanismo de funcionamiento de la visión del mundo y del desarrollo de la inventio que el artista ha representado en el objeto poético, poniendo sobre este un lenguaje de mayor o menor extensión conceptual.

\section{B. 1. Las metáforas orientacionales, ontológicas y estructurales en la poesía erótica de Belli}

Lakoff y Johnson (2009) distinguen tres tipos de metáforas: las orientacionales, las ontológicas y las estructurales. A continuación, veremos algunos tipos de metáforas que expone la poética erótica de Belli.

El primer tipo de metáforas son las orientacionales, pues organizan un sistema global de conceptos con relación a otros y tienen que ver con la orientación espacial: arriba-abajo, dentro-fuera, delante-detrás, profundo-superficial, central-periférico, etc. Al decir de los teóricos estas orientaciones espaciales surgen del hecho de que tenemos un cuerpo de tipo determinado y que actúa como funciona en nuestro medio físico (Lakoff \& Johnson, 2009, p 39).

En la poesía de Belli, estos tipos de metáforas refieren la relación dentro y fuera, como el reconocimiento interior frente al exterior del cuerpo, del acto 
sexual frente a la contemplación erótica, de la vida social frente a la vida íntima, etc. El mismo autor, asimismo, publica un libro de temática variable que titula Dentro É fuera (1960). En este hay un epígrafe de José Ortega y Gasset que refiere la necesidad (también curiosidad) de analizar y describir el funcionamiento particular del cuerpo desde dentro para observar el paisaje interior de aquel. Sin duda, este tipo de metáforas orientacionales se dejan notar en poemas como "Algún día el amor" (;Ob Hada Cibernética!, 1962), donde se leen estos versos "no dentro de los ojos, sino fuera, / invisible, más perenne, / si de fuego no, de aire" (p. 52); en el texto "A la noche" (Sextinas y otros poemas, 1970), se leen "Abridme vuestras piernas / y pecho y boca y brazos para siempre, / que aburrido ya estoy / de las ninfas del alba y del crepúsculo, / y reposar las sienes quiero al fin / sobre la Cruz del Sur / de vuestro pubis aún desconocido, / para fortalecerme / con el secreto ardor de los milenios" (p. 150); en el poema "Del lecho botánico al lecho humano" (El buen mudar, 1987), se leen los siguientes versos "Esta noche dispone el hortelano / que en el lecho botánico se enlacen / de arriba abajo escrupulosamente / como una sola planta que florece / por la ley de la inercia día a día" (p. 309); en el texto, "El presagio" (Bajo el sol de la media noche rojo, 1990), se leen "!Arriba, pastor, las manos!, / Y entrégueme a la pacífica / por el resto de los siglos / y los siglos. Así sea” (p. 398); en el poema, “Cuándo, señora mía...?” (Bajo el sol de la media noche rojo, 1990), donde se lee “¿Cuándo, señora mía, dormiremos / por primera vez entre cielo y suelo, / como aves en el seno de su nido, / dos peces en el vasto mar, / olmo y liana en el bosque pegadísimos / hasta coronar una sola planta?" (p. 393) y en el poema "No salir jamás" (Bajo el sol de la media noche rojo, 1990), se pueden advertir estos versos “¿Cuándo, cuándo de nuevo volveré / en qué minuto, día, año o centuria, / al sacro rinconcillo de mi dueña, / paraje oculto para mí guardado, / y a merced de su excelsa carne allí / yacer adentro y no salir jamás?” (p. 418).

El segundo tipo de metáforas son las ontológicas, que refieren a que nuestras experiencias físicas con objetos físicos (nuestro propio cuerpo) proporcionan la base para una variedad extraordinariamente amplia de metáforas ontológicas. De esta forma se puede considerar acontecimientos, actividades, emociones, ideas, etc., como entidades y sustancias (Lakoff \& Johnson, 2009, p. 63). Verbigracia, la expresión "la mente es una máquina", puede resultar ilustrativa para explicar el funcionamiento de la metáfora ontológica. En la poesía erótica de Belli, este poema puede ayudarnos a observar el funcionamiento de esta metáfora:

\section{No salir jamás}

¿Cuándo, cuándo de nuevo volveré en qué minuto, día, año o centuria, al sacro rinconcillo de mi dueña, 
paraje oculto para mí guardado, y a merced de su excelsa carne allí yacer adentro y no salir jamás? A aquel lugar yo quiero retornar, hasta el punto central eternamente, introducido en el secreto valle, y en ella cuerpo y alma así cuajado. No quiero nada más sino volver adonde fugazmente ayer estuve, cruzar el umbral con seguro paso y ahora para siempre allí quedarme, no como dueño de un terrenal sitio, mas por entero rey del universo.

(Belli, 2008, p. 418)

El poema desarrolla un pensamiento metafórico ontológico de la siguiente manera. El cuerpo aludido como carne es un objeto recipiente del deseo del locutor; asimismo, la parte sexual (representada como rinconcillo, la excelsa carne, el secreto valle) es también una sustancia recipiente del sexo del locutor personaje en el poema. De esta manera, la erotización del órgano sexual no agota la sexualidad, sino que crea una atmósfera de ritualización del acto coital, pues los adjetivos "sacro rinconcillo", "paraje oculto", "excelsa carne", "secreto valle", "rey del universo", refieren la trascendencia que conlleva el goce del cuerpo más allá del hedonismo.

El tercer tipo de metáforas son las estructurales, estas nos permiten mucho más que orientar conceptos, referirnos a ellos, cuantificarlos, etc. Más precisamente, posibilitan utilizar un concepto muy estructurado y claramente delineado para estructurar otro. Las metáforas estructurales se fundamentan en correlaciones sistemáticas dentro de nuestra experiencia (Lakoff \& Johnson, 2009, p. 101).

Un buen ejemplo es el poema "Por qué me han mudado” (¡Ob Hada Cibernética!, 1962), donde se lee:

¿Por qué me han mudado

del claustro materno

al claustro terreno,

en vez de desovarme

en agua o aire o fuego?

(Belli, 2008, p. 49) 
Efectivamente, en el poema, un concepto estructura a otro. Es así que el concepto de "claustro materno" sirve para referirse al de "claustro terreno"; sin embargo, es en el segundo concepto donde "claustro", de origen latino y referido a un espacio cerrado, imposibilita y anula la libertad, mientras que en el primero (en el materno) era el espacio de refugio y seguridad, pues representa un vínculo más humano. Por ello el cuestionamiento del locutor en el poema sobre lo "terreno", vinculado al ámbito social y deshumanizante. Sin embargo, aparece otro concepto estructural que refiere a otro concepto: la forma del nacimiento humano frente al de las otras especies. En el caso humano, ese mudar o ese nacimiento se produce de la madre a la sociedad, de ahí el tono interrogativo no para preguntar, sino para expresar un sentimiento de inconformidad y desconcierto; en el caso de las otras especies, se manifiesta en los últimos versos donde refiere al desove, lo particular de esta referencia es que el locutor advierte que aquella relación es más natural, pues conecta al ser con las energías arquetípicas: agua, fuego, aire y tierra.

\section{B.2. E1 discurso erótico deglutiente}

Los procesos del pensamiento humano son de naturaleza metafóricos. De esta manera, el sistema conceptual desempeña un papel fundamental en la definición de nuestras realidades más cotidianas como más complejas. Aunque el uso de este no es de naturaleza muchas veces consciente, pues "pensamos y actuamos más o menos automáticamente de acuerdo con ciertas pautas" en situaciones de la vida diaria (Lakoff \& Johnson, 2009, p. 40).

Los teóricos de Metáforas de la vida cotidiana, constantemente emplean la expresión "en nuestra cultura", precisamente al anotar diversos ejemplos de expresiones metafóricas de una cultura en particular, lo cual evidencia que es el planteamiento desde una perspectiva cultural. Esta idea, sin duda, se relaciona con lo que Stefano Arduini (2000) ha denominado a la figura retórica (entre ellas al tropo de la metáfora) como "un universal antropológico de la expresión" (p. 155)

Para Alarcón Fernández (2002) "la metáfora, en consecuencia, no se restringe al lenguaje, como se pensó durante mucho tiempo" (p. 8), sino que más bien refiere complejos procesos de pensamiento humano que son en gran parte metafóricos y se manifiestan por medio del lenguaje.

La perspectiva lingüístico-cognitiva ha ayudado a observar precisamente a la metáfora más allá de la literatura como artificio, más allá de la expresividad, sino como una forma de categorizar, representar y sistematizar nuestra percepción de la realidad. De tal manera que, ejemplos como: "sus consejos me iluminaron", "me salté la página”, "ponte las pilas", "su mirada la devoró”; no 
son meras expresiones, sino que estas obedecen a nuestro sistema conceptual, el cual está construida en la experiencia con la realidad sensible. De esta manera:

encontramos expresiones pertenecientes al dominio de la COMIDA, tales como: "tener apetito", "saciar el hambre", "comida apetitosa", en el dominio del SEXO, de acuerdo con la metáfora EL ACTO SEXUAL ES COMER. (Alarcón Fernández, 2002, p. 9)

Es así que el deseo, lo apetecible de la comida y el placer provocado son los componentes que se trasladan al dominio meta del SEXO.

Veamos cómo se representa esta relación entre el "acto de comer" y el "acto sexual” en la poesía erótica de Carlos Germán Belli, pues esta no solo se reduce a la expresión, sino que exhibe una representación metafórica compleja.

Hay varios poemas que refieren este pensamiento metafórico. Por ejemplo, en el poema "Cuando el amor es como la gula voraz" (El alternado paso de los hados, 2006) se leen en estos versos: "Adán sublunar a más no poder/ besa como chupándose los dedos / bajo la ley de la voracidad, / y su alma se aproxima muy resulta / al gran hambre y ardoroso amor, / naciendo en ella una identidad nueva / cuando el ansioso humano / asume toda la avidez del vientre, / y entonces por el gusto se aceleran / los latidos del corazón puntuales" (p. 595); en otro texto, "Sextina de Kid y Lulú" (Sextinas y otros poemas, 1970), se lee: "Kid el Liliputiense ya no sobras / comerá por primera vez en siglos, / cuando aplaque su cavernario hambre / con el condimentado dorso en guiso/ de su Lulú la Belle hasta la muerte, / que idolatrara aun antes de la vida" (p. 153); en otro poema "Res, res mía" (En alabanza del bolo alimenticio, 1979), se lee: "si te quiero / por quintales / en el bolo / de alimentos (...) no comprendes / que yo vivo / cuán pendiente / de tus trozos" (p. 237); en otro texto, "La albóndigas" (En alabanza del bolo alimenticio, 1979), se lee: "Esas, esas de Filis mil albóndigas, / de cuán sabrosa carne tipo "A», / \& ralladuras de terrestre pan, / entremezclado con especia \& huevos; / de ese pues picadillo únicamente / una pizca de la A carnal quisiera” (p. 229); o en este otro poema “iAbajo las lonjas!” (;Oh Hada cibernética!, 1962), se lee:

\author{
¡Abajo las lonjas! \\ ¡Oh Hada Cibernética!, \\ cuándo de un soplo asolarás las lonjas, \\ que cautivo me tienen, \\ y me libres al fin \\ para que yo entonces pueda \\ dedicarme a buscar una mujer \\ dulce como el azúcar,
}


suave como la seda, y comérmela en pedacitos,

y gritar después:

“¡abajo la lonja de azúcar, abajo la lonja de la seda!"

(Belli, 2008, p. 60)

Evidentemente el poema manifiesta el pensamiento metafórico referido al ámbito erótico. Observemos cómo funcionan los componentes en este texto. Por un lado, aparece el locutor del poema quien, a partir de una apelación (apóstrofe), busca en su interlocutor (el hada cibernética) los favores y la magia divina para desprenderse de las ataduras (lonjas) que no le permiten gozar plenamente del favor de la amada (una mujer). La representación que establece el locutor personaje para caracterizar a la mujer "dulce como el azúcar" y "suave como la seda", comprenden al símil o comparación (perteneciente al campo figurativo de la metáfora). En ambos casos se ponen en funcionamiento dos elementos sensoriales como el gusto (agradable, referido al carácter) y el tacto (joven, referido a la suavidad de la piel). De esta manera, estos dos versos se relacionan con el siguiente, donde se lee "y comérmela en pedacitos", donde observamos el verso referido al dominio de la COMIDA (comer), en el dominio del SEXO, de acuerdo con la metáfora EL ACTO SEXUAL ES COMER. Asimismo, también aparece un tono coloquial en este verso, pero este celebra la posesión del cuerpo ("pedacitos") que llega al éxtasis en el verso "y gritar después". Los dos últimos versos refieren a desprenderse de las lonjas (lo que cubre el carácter, desnudarse, desvestir el alma), que es metáfora ENTREGARSE ES DESVESTIRSE. Porque como señala Pierre Guiraud (1986) sobre el cuerpo: "El campo semántico de esas analogías corporales ocupa un lugar importante en el ámbito de nuestros conocimientos del lenguaje que las expresa y las estructura" (p. 49).

Por ello, esta representación es muy usual en la poética erótica de Belli, y está ligada al acto de comer. A veces el cuerpo erotizado se presenta como una lonja, como una albóndiga, como un filete, como una tortilla, como res, o simplemente como cuerpo. Pero sobre este opera un deseo frenético, casi insaciable que es la fuerza generadora del impulso vital, ligado al tiempo mitológico y al descubrimiento de la sexualidad humana, he ahí por ello la referencia a Adán y Eva en muchos poemas.

Asimismo, el amor se instala en el ámbito de la cotidianidad que es la ritualidad íntima de los cuerpos (el alimento exterior ingresa y nutre al ser interior, como metáfora de la trascendencia), pues comer supone un encuentro cotidiano entre el deglutiente y lo anhelado, lo deseado, lo apetecido, lo erotizado; lo mismo que el amante frente al cuerpo de la amada. Es así que desde la visión de Belli, el cuerpo, representado metafóricamente, es un espacio simbólico de 
encuentros y desencuentros, no es el cuerpo femenino un mero objeto sexualizado, sino el lugar de la creación por excelencia en el sentido más amplio, donde el ser retorna para nacer nuevamente de este.

\section{B.3. E1 discurso erótico vigilante}

Hemos señalado en la sección anterior que el cuerpo es el espacio donde se producen las más complejas simbolizaciones. Lenguaje y cuerpo denotan por ello múltiples signos que expelen información importante.

Es así que el cuerpo denota signos estructurales y organizados que adquieren sentido cuando estos, precisamente, se relacionan con otros; entonces, es cuando imaginamos nuestro mundo a partir del cuerpo (Guiraud, 1986).

Michael Foucault (2003), en su libro Vigilar y castigar, ha señalado que:

el cuerpo está también directamente inmerso en un campo político; las relaciones de poder operan sobre él como una presa inmediata; lo cercan, lo marcan, lo doman, lo someten a suplicio, lo fuerzan a unos trabajos, lo obligan a unas ceremonias, exigen de él unos signos. (pp. 32-33)

De esta manera, el cuerpo es un espacio simbólico en disputa, pues sobre él operan múltiples discursos y fuerzas que buscan signos que este arroje. En la poética de Belli este cuerpo se haya erotizado, ya sea como una lonja, como una albóndiga, como un filete, como una tortilla, como res, o simplemente como cuerpo. De este modo, el cuerpo femenino (también como sexo), está siempre vigilado a través del locutor personaje y a través de la representación erótica del lenguaje que opera sobre aquel.

Por ejemplo, en el poema "Villanela" (Canciones y otros poemas, 1982), se lee:

\section{Villanela}

Llevarte quiero dentro de mi piel, si bien en lontananza aún te acecho, para rescatar la perdida miel.

Contemplándote como un perro fiel, en el día te sigo trecho a trecho, que haberte quiero dentro de mi piel.

No más el sabor de la cruda hiel, y en paz quedar conmigo y ya rehecho, rescatando así la perdida miel. 
Ni viva aurora, ni oro, ni clavel, $\mathrm{y}$ en cambio por primera vez el hecho de llevarte yo dentro de mi piel.

Verte de lejos no es asunto cruel, sino el raro camino que me he hecho, para rescatar la perdida miel.

El ojo mío nunca te es infiel, aun estando distante de tu pecho, que haberte quiero dentro de mi piel, y así rescatar la perdida miel.

(Belli, 2008, p. 265)

E1 poema "Villanela" de Belli posee 19 versos, distribuidos en seis estrofas. Las cinco estrofas conformadas por 3 versos cada una (5 tercetos) y la sexta estrofa conformada por 4 versos (1 cuarteto). Obedece a la estructura de "la villanella" (forma poética muy utilizada en el Renacimiento), que tiene la particularidad de repetir el primer y último verso de la primera estrofa en las demás estrofas de manera alternada; salvo en la última estrofa del poema, donde aparecen estos dos versos como últimos versos al final de esta. En el poema de Belli, por ejemplo, aparece no solo la estructura formal de la villanela, sino también se circunscribe a la representación de la figura femenina del "campo", a la mujer de la villa a la que le debe el nombre la forma poética, donde el vate peruano coloca un tono particular en esta a partir de la erotización.

En el poema de Belli el locutor personaje se dirige hacia un alocutario no representado, pero que se puede deducir a partir del paratexto del título (villanela) y las referencias espaciales que en la voz del locutor se representan (se refiere al ámbito campestre). Desde la perspectiva del locutor personaje se vislumbra el padecimiento de amor (pasional) no correspondido; por ello, se representa un discurso de vigilancia donde este opera a partir de conceptos como "acechar" (en el 2 verso), "seguir" (en el 5 verso), "verte de lejos" (en el 13 verso) y "el ojo mío nunca te es infiel" (en el 16 verso). Como podemos advertir, este conjunto de palabras tiene semas comunes que pueden resumirse en "vigilar", donde sin duda el verso número 16 es significativo ("El ojo mío nunca te es infiel”), pues la visión del locutor en el poema funciona como un panóptico, donde se acecha, se sigue los pasos, se ve desde lejos y hay cierta fijación por el cuerpo deseado.

Los elementos metafóricos que completan esta idea están en el par metafórico de versos que se repiten alternadamente. Por un lado, "Llevarte quiero dentro de mi piel", que evidentemente refiere al acto de unión corporal, ser un solo cuerpo, y donde encontramos una metáfora orientacional (de relación de fuera-adentro), pues se anhela que el objeto de deseo se incorpore al suyo y su- 
pla así el deseo irrefrenable del locutor personaje. Por otro lado, "para rescatar la perdida miel", refiere la resemantización del concepto de "miel" ligado ahora al concepto de la experiencia del goce sexual, por ello la referencia a un concepto como miel que puede ser percibido sensorialmente por el gusto, y este llevar al placer por medio de la experiencia. Sin duda hay un padecimiento del locutor personaje que solo puede ser remediado con la posesión del cuerpo deseado: "No más el sabor de la cruda hiel, / y en paz quedar conmigo y ya rehecho, / rescatando así la perdida miel", y ante la lejanía, la distancia que hay entre los interlocutores, opera por ello el discurso de la vigilancia sobre el cuerpo.

Como podemos observar, en el poema de Belli, no hay una visión punitiva del cuerpo. Por el contrario, existe un deseo frenético muy ligado al voyerismo (palabra de origen francesa que deriva del verbo voir (ver) en relación con el sufijo de agente -eur, y significa «el que ve») del locutor personaje, pues adopta muchas veces el comportamiento del Sátiro (personaje mitológico que habita el bosque y que posee un exacerbado deseo sexual).

\section{Conclusión}

En muchos poemas eróticos del vate peruano el discurso se torna figurativo, pues devela no solo la comprensión del cuerpo (referencialidad) sino su proceso cognitivo (simbolización) que va más allá del amor y del erotismo como la expresión de una pulsión sexual. El universo figurativo que se observa en la poética belliana coloca en un plano medular la figura femenina; sin embargo, esta figura es sometida a un conjunto de operaciones como la metaforización, la alegorización, la analogización, la comparación, la simbolización, etc., donde el cuerpo femenino entonces se convierte en un espacio de disputa, tensión, posesión y donde diversas dinámicas sígnicas operan sobre él.

\section{Referencias bibliográficas}

Alarcón Fernández, P. (2002). El acto sexual es comer: descripción lingüístico-cognitiva. RLA. Revista de Lingüistica Teórica y Aplicada, 40, p. 7-24.

Arduini, S. (2000). Prolegómenos a una teoría general de las figuras. Murcia: Universidad de Murcia.

Belli, C. G. (2008). Los versos juntos (1946-2008). Poesía completa. Sevilla: Sibilina, Fundación BBVA.

Bordieu, P., Hernández Rodríguez, H. \& Montesinos, R. (1998). La dominación masculina. La masculinidad. Aspectos sociales y culturales (pp. 9-108). Quito: Ediciones Abya-Yala.

Canfield, M. L. (2012). Más que placer un goce exasperante. Libros $\mathcal{E}$ Artes 6 (pp. 52-53), 2-6. 
Cornejo Polar, J. (1994). La poesía de Carlos Germán Belli: Una aproximación. Lima: Universidad de Lima

Fontanille, J. (2006). Semiótica del discurso. Lima: Fondo editorial de la Universidad de Lima.

Foucault, M. (2003). Vigilar y castigar. Buenos Aires: Siglo XXI Editores.

Guiraud, P. (1986). El lenguaje del cuerpo. México D. F.: Fondo de Cultura Económica.

Lakoff, G. \& Johnson, M. (2009). Metáforas de la vida cotidiana. Madrid: Ediciones Cátedra.

Marchese, A. \& Forradellas, J. (1994). Diccionario de retórica, crítica y terminología literaria. Barcelona: Editorial Ariel. 